\title{
Ethnic disparities in parity and child mortality in Nigeria: a multiple indicator cluster survey
}

\author{
Bishwajit Ghose, Sanni Yaya \\ University of Ottawa, Ottawa, Canada
}

\begin{abstract}
Introduction: Women's reproductive or fertility behaviour and overall maternal and child health outcomes are greatly influenced by various biological and psychosocial factors, which themselves seem to vary substantially among different ethnic backgrounds. This study was undertaken on a representative sample of Nigerian women to assess whether: 1) the ethnic disparities in fertility and child mortality rates are significant even after controlling for potential confounders, 2) women who experience higher child mortality have higher fertility rates.

Methods: Cross-sectional data on 34,139 women aged between 15 and 49 years were extracted from a multiple indicator cluster survey conducted in 2017 . The total number of children ever born and self-reported events of child health were used as outcome variables. Ethnic differences in parity and child mortality were analysed using multivariable regression techniques.

Results: Significant ethnic variation was found across fertility and under-five mortality rates. These variations persisted even after adjusting for several potential risk factors. There was an inverse relationship between under-five mortality and fertility. The prevalence of having $>6$ children was highest among women who reported $>2$ child deaths. In the regression analysis, high-parity women were found to have experienced higher child mortalities.

Conclusions: Significant ethnic differences exist in fertility and under-five mortality, which might be indicative of ethnic inequalities in health determinants and access to healthcare resources. The findings also support the view that women who experience child death are more likely to have higher fertilities than those who do not. Future studies should explore the underlying disparities in child mortality and fertility rates in Nigeria.
\end{abstract}

KEY WORDS: ethnicity, fertility, reproductive health, child mortality, Nigeria.

ADDRESS FOR CORRESPONDENCE: Bishwajit Ghose, PhD, 120 University Private, Social Sciences Building, Ottawa, Ontario, K1N 6N5 Canada, e-mail: brammaputram@gmail.com; Mark Parascandola, PhD, MPH, Tobacco Control Research Branch, Behavioural Research Program, Division of Cancer Control and Population Sciences, National Cancer Institute, National Institutes of Health, 9609 Medical Centre Drive, Bethesda, MD, 20892, USA, e-mail: paramark@mail.nih.gov

\section{INTRODUCTION}

In recent decades, the non-biological determinants of health and illness such as racial, ethnic, sociocultural, and psychosocial factors have been receiving growing research and policy attention $[1,2]$. This has brought about a deeper appreciation and understanding of the ethnic disparities in the distribution of the risk factors, incidence, and survival from certain diseases. Including ethnicity in the broader concept of social determinants of health $(\mathrm{SDH})$ holds great potential for innovation and efficiency in healthcare delivery models. At the same time, the ethnic influences on reproductive norms, values, and behaviour, such as fertility preferences and desired family sizes, are also gaining traction [3-5]. Studies on the ethnic aspects of population, including other social determinants, are especially important for countries with high rates of population growth and child mortality. 
Ethnicity and tribalism as a subject matter is relatively less prominent in the areas of population health research and planning in African countries, which is probably due to an underappreciation of the unique health patterns and needs of the diverse demographics across and within countries. Countries in sub-Saharan Africa have been struggling to sustainably address the reproductive health needs of the population $[6,7]$. Poor coverage and utilisation of family planning services, high fertility, and high maternal and child mortality rates are the terms that describe the state of public health and healthcare systems in the region. While some countries are experiencing rapid progress through strategic planning and intervention plans, such as Millennium and Sustainable Development Goals (MDGs and SDGs) [8, 9], the situation remains challenging for countries having a large population with diverse geography and ethnic communities, as seen in Nigeria $[10,11]$.

Nigeria boasts a population of rich cultural diversity with over 250 ethnic groups [12]. As the most populous country in sub-Saharan Africa, Nigeria has one of the highest maternal and child mortality rates in the continent. National population control policy has been investing in controlling fertility and reducing child mortality to make essential maternal healthcare and family planning services more accessible to an increasingly high proportion of the population. Nonetheless, considerable disparities exist in terms of service utilisation and maternal and child mortality rates across regional and socioeconomic groups. Previous studies on reproductive health issues in Nigeria have mainly focused on social and economic determinants, with little emphasis on exploring the influences of ethnicity. As globalisation progresses, the country is undergoing rapid transformation in various social and national aspects. At the same time, the presence of ethnic influences on people's belief system, cultural practices, and political sphere have remained vivid till today [13-15].

Ethnicity can influence health mainly through an individual's perception of and attitude towards health and medical care, traditional values for care-seeking, and the power hierarchy of family members in health decision making. Previous studies provide evidence of ethnic variations in health care utilisation in Nigeria. For example, uptake of antenatal and postnatal care were found to be lower among Hausa women compared to their Igbo and Yoruba counterparts [16]. Hausa women of Northern Nigeria have less freedom to go out in public due to ethnic traditions such as purdah (i.e. wife seclusion), which can substantially limit women's autonomy to get essential medical treatment by themselves [17]. This situation can be especially challenging for pregnant women and new mothers and can cause life-threatening risks to themselves and their infants. Important associations of ethnic characteristics with under-five mortality were also reported by observational studies in Nigeria $[18,19]$. Although understanding the precise underly- ing sociocultural pathways of these associations would require qualitative investigations into the matter, up-todate findings from quantitative studies provide the necessary backgrounds for undertaking more in-depth studies. With this in mind, we carried out this study using the latest multiple indicator cluster survey (MICS) in Nigeria. MICS is a nationally representative survey that provides information on various health and sociocultural backgrounds on adult women including fertility and child mortality. The findings of this study reflect the latest information on fertility and under-five mortality in Nigeria. Additionally, we attempted to investigate whether experiencing child death increases the likelihood of having higher parity. Higher parity is generally associated with higher rates of child mortality, and vice versa. In communities where child mortality is a common issue, parents may want to have more children in order to have the expected number of living children. Understanding the ethnic disparities in these indicators is crucial for evidence health and public policy making in a country that finds itself in the grips of exacerbating maternal and child health conditions.

\section{MATERIAL AND METHODS \\ SETTING}

Nigeria is situated in West Africa and shares frontiers with Benin, Chad, Cameroon, and Niger. Composed of 36 states and a Federal Capital Territory, Nigeria is divided into six geopolitical zones classified on the basis of cultural and ethnic similarity and common historical background. The country is generally referred to as "The Giant of Africa," due to the sheer population size (about 1/6 of the continent) and distinct economic progress as the largest oil producing country in the region. Apart from the economic achievements, the country also boasts a rich ethnic and cultural diversity with several hundred ethnic groups and over 500 languages spoken. The Hausa are the biggest ethnic group making up approximately a quarter of the total population, while Yoruba and Igbo make up, respectively, about $21 \%$ and $18 \%$ of the population of Nigeria [20].

\section{SURVEY AND DATA SOURCE}

The fifth round of the Nigeria Multiple Indicator Cluster Survey (MICS) was conducted in 2016-2017 by the National Bureau of Statistics (NBS) with technical support provided by the United Nations Children's Fund (UNICEF) and under the financial auspices of the World Health Organisation (WHO), World Bank, Save One Million Lives (SOML), Bill and Melinda Gates Foundation, United Nations Population Funds (UNFPA), United States Agency for International Development (USAID), and the United Nations Children's Fund (UNICEF). MICS surveys are carried out periodically as part of the global MICS program. The main objectives are generating quality data for monitor- 
ing progress towards essential health and development indicators such as child-mortality, maternal healthcare services utilisation rates, knowledge about HIV/AIDS, along with various sociodemographic variables. The ultimate aim of the program is to facilitate evidence-based decision-making for health programs and policymakers.

This nationwide survey was conducted on adult men and women residing in rural and urban areas of all six geopolitical zones of Nigeria. MICS surveys employ a two-stage sampling strategy, with the first stage being the selection of Enumeration Areas (EAs) within the strata, while the second stage is the selection of households within each EA. The states within the geopolitical zones serve as the sampling strata, with the EAs within each state serving as the Primary Sampling Units. Four sets of questionnaires were used for households, men, women, and children under five years old. Data for this study were drawn from the women's survey. In total, 36,176 women aged 15-49 years were selected for the survey, of whom 34,376 were successfully interviewed, generating a response rate of $95.0 \%$. More details on sampling, field work, and data entry are available from the final reports published by UNICEF MICS [21].

\section{MEASURES}

The outcome measures were: 1) total number of childbirths per woman and 2) experience of child death. Women were asked to report the total number of children ever born to them and the number of their children who had ever died. The number of childbirths was categorised as: $\leq 4$ and $>4$. Information on child death was collected by asking the mothers whether or not there was any child who ever died. It was categorised as: yes and no. The main independent variable in the analysis was the ethnic identity of the participants. The survey dataset included the following ethnic groups: Hausa, Igbo, Yoruba, and other.

Besides the main explanatory variables, the following factors were likely to be correlated with parity and child death and were used as control variables: age groups (15-24, 25-29, 30-34, and 35-49); residency (rural/ urban); geopolitical region: North Central, North East, North West, South East, South South, and South West; religion (Christian, Islam, and other); educational status (nil, primary, secondary, and higher); wealth index (poorest, poorer, middle, richer, richest); and received ANC care (yes/no).

\section{DATA ANALYSIS}

Data were analysed using SPSS version 24. First, the datasets were checked for missing values and outliers and then merged to perform pooled analysis. Owing to the clustered structure of MICS data, we used a complex survey design method for all analyses. Sociodemographic variables were compared between parity ( $\leq 4$ vs $>4$ ) and child mortality (child died vs no child died) by percent- ages with 95\% CIs. Pearson correlations tests were used to measure the statistical significance of these bivariate associations. The variables that showed significance at $p \leq 0.25$ in the bivariate tests were retained for final regression analysis. The variance inflation factor was used to check for multicollinearity among the variables included in the model. Multicollinearity was not found to be a concern (variance inflation factor $<10$ ). The association between parity and child death with ethnicity was measured by binary logistic regression models. The first model included no other variables to measure the unadjusted odds ratios, while the second model controlled for the potentially confounding variables to produce the adjusted odds ratios. Same method was applied to calculate the association between parity and child mortality among different ethnic groups. Results of regression analyses were presented as odds ratios with $95 \%$ CIs. All tests were two-tailed, and associations were considered statistically significant at a $p$-value of $<0.05$.

\section{ETHICS STATEMENT}

Ethical approval was not necessary for this study because the data were secondary and are available in public domain in anonymised form.

\section{SAMPLE PROFILE}

The basic sociodemographic characteristics of the sample population are presented in Table 1 . The analysis included 34,139 women aged between 15 and 49 years with the mean age of 29.8 years (SD 7.63). A larger proportion of the women were in the youngest age group of $15-19$ years (19.6\%), rural residents $(68.1 \%)$, located in the North West region (27.2\%), had secondary level education $(39.1 \%)$, living in the households with richest wealth status or highest wealth quintile $(22.9 \%)$, and received antenatal care $(69.3 \%)$. The majority of the women belonged to the Hausa ethnic group (39.3\%), followed by Igbo (13.9\%) and Yoruba (12.5\%).

More than a quarter of the women had given birth to more than four children $(28.1 \%, 95 \% \mathrm{CI}=27.3-29.0)$, and more than one-fifth reported experiencing child death $(21.4 \%, 95 \% \mathrm{CI}=20.5-22.4)$. The percentage of those who had $>4$ children and experienced child death was higher among women aged 30-34 years, rural residents, living in the North west region, with no formal education, from the households with poorest wealth status, who did not receive antenatal care, and belonged to the Hausa ethnic group.

Figure 1 illustrates noticeable ethnic disparities in child mortality in Nigeria. It appeared that Hausa women were more likely to report child death of any frequency than Igbo, Yoruba, or other ethnic groups.

Yoruba women had the highest prevalence of having 1-2 and 3-4 children, while that of having 5-6 and $>6$ children was highest among Hausa women (Fig. 2). 
TABLE 1. Sample characteristics. Nigeria MICS 2017

\begin{tabular}{|c|c|c|c|c|c|}
\hline \multirow[t]{2}{*}{ Variables } & \multirow[t]{2}{*}{$n=34,139(\%)$} & \multicolumn{2}{|c|}{ No. of children ever born } & \multicolumn{2}{|c|}{ No. of children ever died } \\
\hline & & $\begin{array}{c}>4 \\
28.1 \% \\
(27.3-29.0)\end{array}$ & $\begin{array}{c}\leq 4 \\
71.9 \% \\
(71.0-72.7)\end{array}$ & $\begin{array}{c}\text { Yes } \\
21.4 \% \\
(20.5-22.4)\end{array}$ & $\begin{array}{c}\text { No } \\
78.6 \% \\
(77.6-79.5)\end{array}$ \\
\hline \multicolumn{6}{|l|}{ Age groups } \\
\hline $15-19$ & 6706 (19.6) & $1.0(0.7-2.1)$ & $27.3(26.5-28.1)$ & $2.0(1.6-2.4)$ & $24.4(23.7-25.1)$ \\
\hline $20-24$ & $5674(16.6)$ & $1.0(0.7-1.3)$ & $23.2(22.4-24.0)$ & $9.0(8.1-9.9)$ & $19.1(18.5-19.8)$ \\
\hline $25-29$ & $5905(17.3)$ & $10.2(9.2-11.2)$ & $20.1(19.4-20.7)$ & $16.3(15.2-17.5)$ & $17.5(16.9-18.2)$ \\
\hline $30-34$ & $5277(15.5)$ & $21.9(20.9-23.0)$ & $13.2(12.6-13.8)$ & $19.3(18.2-20.5)$ & $14.6(14.0-15.3)$ \\
\hline $35-39$ & $4378(12.8)$ & $25.6(24.5-26.7)$ & $7.7(7.3-8.3)$ & $20.6(19.4-21.8)$ & $10.6(10.1-11.1)$ \\
\hline $40-44$ & $3590(10.5)$ & $22.4(21.4-24.5)$ & $5.3(4.9-5.6)$ & $18.1(17.0-19.2)$ & $8.3(7.9-8.7)$ \\
\hline $45-49$ & $2609(7.6)$ & $17.9(17.0-18.9)$ & $3.3(3.0-3.5)$ & $14.8(13.6-15.9)$ & $5.4(5.1-5.7)$ \\
\hline \multicolumn{6}{|l|}{ Residence } \\
\hline Urban & $10,890(31.9)$ & $26.3(23.1-29.6)$ & $39.2(36.2-42.3)$ & $23.2(20.4-26.3)$ & $38.9(35.9-42.1)$ \\
\hline Rural & $23,249(68.1)$ & $73.7(70.4-76.9)$ & $60.8(57.7-63.8)$ & $76.8(73.7-79.6)$ & $61.1(57.9-64.1)$ \\
\hline \multicolumn{6}{|c|}{ Geopolitical region } \\
\hline North Central & $6968(20.4)$ & $16.4(14.6-18.3)$ & $18.0(16.3-19.8)$ & $15.3(13.5-17.3)$ & $18.1(16.4-20.0)$ \\
\hline North East & $5186(15.2)$ & $24.1(21.0-27.5)$ & $17.3(15.2-19.6)$ & $22.3(19.7-25.1)$ & $18.4(15.9-21.1)$ \\
\hline North West & $9286(27.2)$ & $38.4(35.7-41.1)$ & $26.2(24.3-28.1)$ & $41.9(39.1-44.8)$ & $26.2(24.2-28.3)$ \\
\hline South East & $3623(10.6)$ & $5.4(4.6-6.4)$ & $8.4(7.4-9.6)$ & $3.8(3.1-4.5)$ & $8.6(7.6-9.8)$ \\
\hline South South & $4702(13.8)$ & $7.2(6.4-8.1)$ & $13.0(11.6-14.5)$ & $6.3(5.6-7.2)$ & $12.7(11.4-14.2)$ \\
\hline South West & $4374(12.8)$ & $8.5(7.4-9.9)$ & $17.1(14.9-19.7)$ & $10.4(8.9-12.1)$ & $15.9(13.8-18.3)$ \\
\hline \multicolumn{6}{|c|}{ Educational status } \\
\hline None & $11,978(35.1)$ & $57.3(55.1-59.4)$ & $29.4(27.5-31.3)$ & $57.6(55.2-60.0)$ & $31.7(29.7-33.7)$ \\
\hline Primary & 5185 (15.2) & $20.9(19.7-22.1)$ & $12.6(11.9-13.2)$ & $20.3(18.8-21.8)$ & $13.4(12.8-14.1)$ \\
\hline Secondary & $13,346(39.1)$ & $17.5(16.2-19.0)$ & $45.2(43.7-46.8)$ & $18.0(16.5-19.7)$ & $42.7(41.2-44.3)$ \\
\hline Higher & $3630(10.6)$ & $4.3(3.7-5.0)$ & $12.8(11.8-13.9)$ & $4.1(3.5-4.8)$ & $12.2(11.2-13.2)$ \\
\hline \multicolumn{6}{|l|}{ Wealth index } \\
\hline Poorest & $5819(17)$ & $24.8(22.6-27.1)$ & $14.0(12.8-15.3)$ & $25.6(23.3-28.1)$ & $14.7(13.4-16.1)$ \\
\hline Second & $6601(19.3)$ & $22.8(21.3-24.5)$ & $16.6(15.5-17.9)$ & $24.8(23.1-26.6)$ & $16.6(15.5-17.9)$ \\
\hline Middle & $6758(19.8)$ & $20.5(19.0-22.2)$ & $19.2(17.9-20.5)$ & $21.0(19.3-22.7)$ & $19.2(18.0-20.5)$ \\
\hline Fourth & $7131(20.9)$ & $19.0(17.4-20.8)$ & $22.0(20.8-23.2)$ & $16.3(14.6-18.2)$ & $22.5(21.2-23.8)$ \\
\hline Richest & $7830(22.9)$ & $12.8(11.4-14.3)$ & $28.2(26.0-30.4)$ & $12.3(10.9-13.9)$ & $27.0(24.9-29.2)$ \\
\hline \multicolumn{6}{|c|}{ Received ANC care } \\
\hline Yes & $7747(69.3)$ & $35.1(32.5-37.9)$ & $27.1(25.1-29.2)$ & $36.5(33.5-39.5)$ & $27.3(25.3-29.4)$ \\
\hline No & $3428(30.7)$ & $64.9(62.1-67.5)$ & 72.9 (70.8-74.9) & $63.5(60.5-66.5)$ & 72.7 (70.6-74.7) \\
\hline \multicolumn{6}{|l|}{ Ethnicity } \\
\hline Hausa & $13,400(39.3)$ & $57.7(54.9-60.4)$ & $39.0(36.7-41.5)$ & $60.3(57.6-63.0)$ & $39.9(37.4-42.5)$ \\
\hline Igbo & 4755 (13.9) & $7.3(6.3-8.3)$ & $12.3(11.0-13.6)$ & $5.5(4.7-6.4)$ & $12.3(11.1-13.7)$ \\
\hline Yoruba & 4279 (12.5) & $7.8(6.7-8.9)$ & $15.7(14.1-17.5)$ & $9.1(7.9-10.5)$ & $14.7(13.2-16.3)$ \\
\hline Others & $11,705(34.3)$ & $27.3(25.0-29.7)$ & $32.9(30.9-35.1)$ & $25.1(22.9-27.4)$ & $33.1(30.9-35.3)$ \\
\hline
\end{tabular}

Figure 3 demonstrates an inverse relationship between the percentages of child mortality and parity. Women who reported no child death had the highest percentages of having one (25\%) and lowest percentag- es of having more than four (16.6\%) children. The percentages of having more than 3-4, 5-6, and $>6$ children increased almost linearly with additional number of child deaths. 


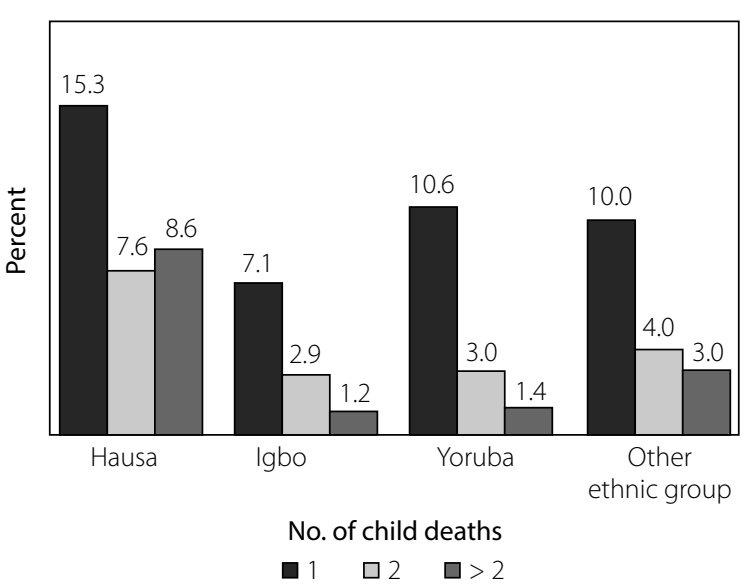

FIG. 1. Ethnic disparities in experiencing child death among Nigerian women (\%)

\section{MULTIVARIABLE REGRESSION ANALYSIS}

Table 2 indicates that the odds of having $>4$ children $(\mathrm{OR}=1.573 ; 95 \% \mathrm{CI}=1.291-1.918)$ and reporting child death $(\mathrm{OR}=1.379 ; 95 \% \mathrm{CI}=1.121-1.697)$ were higher among Hausa women compared with women of other ethnic groups; whereas for Igbo women, the odds were lower for both of these indicators. The association between parity and child death was valid for Hausa (OR $=1.379 ; 95 \% \mathrm{CI}=1.121-1.697)$ and Igbo $(\mathrm{OR}=0.582$; $95 \% \mathrm{CI}=0.396-0.855$ ) women only.

The results of the association between parity and child mortality are shown in Table 3 . It revealed a considerably strong positive association between parity and child mortality even after adjusting for control variables.

\section{DISCUSSION}

\section{MAIN FINDINGS}

The findings of the study reveal significant association between ethnicity and fertility behaviour and child death among Nigerian women. The prevalence of child mortality and high parity was greater among Hausa women compared with Igbo and Yoruba women. The prevalence of having up to two and up to four children was highest among Yoruba women, whereas that of having up to six and more than six children was highest among Hausa women. The prevalence of experiencing child death was higher among women aged 30-34

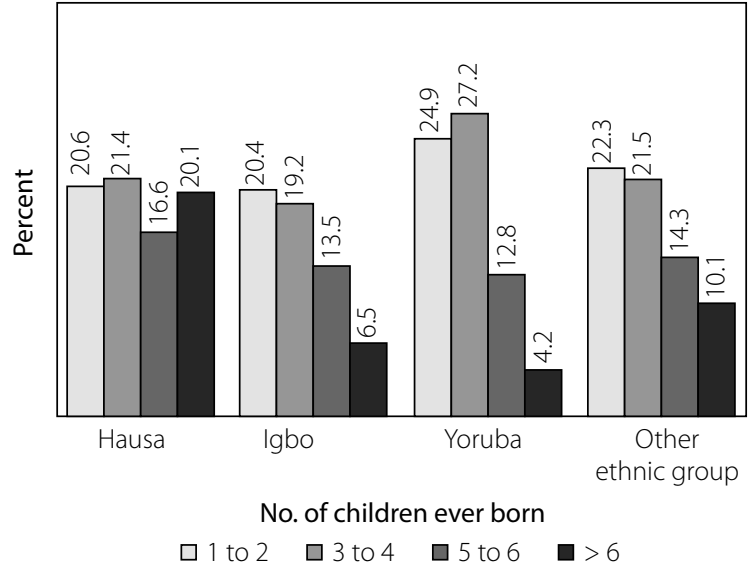

FIG. 2. Ethnic disparities in fertility rates among Nigerian women (\%)

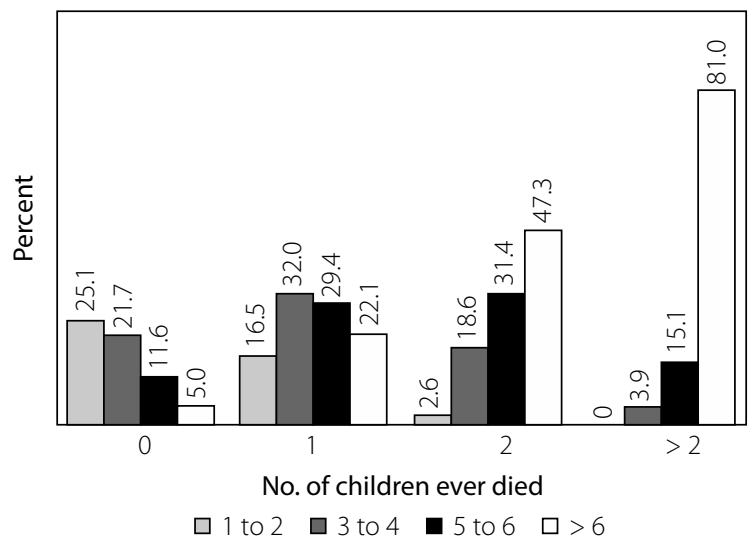

FIG. 3. Total number of childbirths stratified by frequency of child deaths (\%)

years, living in rural areas, located in the North west region, with no formal education, living in households with poorest wealth status, not receiving antenatal care, and belonging to Hausa ethnicity. In the multivariable analysis, the odds of having more than four children was found to be highest among Hausa women. The strength of these associations slightly reduced but remained statistically significant even after adjusting for a range of control variables including age, and educational and wealth status. These findings suggest that ethnicity plays a strong independent role in fertility preference and child

TABLE 2. Multivariable association of parity and child mortality with ethnicity in Nigeria

\begin{tabular}{|l|c|c|c|c|}
\hline \multirow{2}{*}{ Ethnicity } & \multicolumn{2}{|c|}{ Odds of having $>4$ children } & \multicolumn{2}{c|}{ Odds of reporting child death } \\
\cline { 2 - 5 } & $\begin{array}{c}\text { UOR } \\
(95 \% \mathrm{Cl})\end{array}$ & $\begin{array}{c}\text { AOR } \\
(95 \% \mathrm{Cl})^{*}\end{array}$ & $\begin{array}{c}\text { UOR } \\
(95 \% \mathrm{Cl})\end{array}$ & $\begin{array}{c}\text { AOR } \\
(95 \% \mathrm{CI})^{*}\end{array}$ \\
\hline Hausa vs Other & $1.782(1.644-1.932)$ & $1.573(1.291-1.918)$ & $1.993(1.780-2.232)$ & $1.379(1.121-1.697)$ \\
\hline Igbo vs Other & $0.715(0.639-0.799)$ & $0.626(0.405-0.968)$ & $0.588(0.514-0.674)$ & $0.582(0.396-0.855)$ \\
\hline Yoruba vs Other & $0.596(0.520-0.682)$ & $0.723(0.474-1.102)$ & $0.816(0.711-0.938)$ & $1.128(0.845-1.505)$ \\
\hline
\end{tabular}

N.B. reference category - having $>4$ children, UOR - unadjusted odds ratio, $\mathrm{Cl}$ - confidence interval, AOR - adjusted odds ratio, " adjusted for women's age, residency, geopolitical zone, education, household wealth status, received ANC care 
TABLE 3. Multivariable association between high parity (> 4 children) and child mortality among different ethnic groups in Nigeria

\begin{tabular}{|l|c|c|}
\hline Ethnicity & $\begin{array}{c}\text { UOR } \\
(95 \% \mathrm{CI})\end{array}$ & $\begin{array}{c}\text { AOR } \\
(95 \% \mathrm{CI})^{*}\end{array}$ \\
\hline Hausa & $8.553(7.565-9.671)$ & $3.886(3.105-4.863)$ \\
\hline Igbo & $10.578(8.204-13.639)$ & $4.206(2.578-6.862)$ \\
\hline Yoruba & $11.343(8.954-14.370)$ & $5.920(3.697-9.481)$ \\
\hline Others & $10.033(8.725-11.536)$ & $5.029(3.631-6.966)$ \\
\hline Overall & $10.059(9.255-10.934)$ & $3.992(3.436-4.637)$ \\
\hline
\end{tabular}

$N . B$. reference category - having $<4$ children, UOR - unadjusted odds ratio, $\mathrm{Cl}$ - confidence interval, $A O R$ - adjusted odds ratio, " adjusted for women's age, residency, geopolitical zone, education, household wealth status, received ANC care

survival in Nigeria. Women who reported experiencing child death were also more likely to have more than four children. The percentages of having up to four, six, and more than six children showed an almost linear increase with an additional number of child deaths. It is, however, important to note that the analysis was cross-sectional, and therefore the associations cannot be assumed as causality. Because the data were secondary, the choice of control variables was limited, which means that the analysis was not possible to adjust for some crucial confounding factors such as cultural beliefs, and dietary and health practices during pregnancy for mother and after pregnancy for the neonates, which are thought to have a strong influence on child mortality.

\section{PREVIOUS EVIDENCE}

Although evidence on fertility preference is scarce, several cross-sectional studies have been conducted during the past two decades concerning the differential influence of ethnic affiliations on child mortality in Nigeria. However, the findings are not readily comparable due to differences in survey design and methodological approaches used. Consistent with the results of the present analysis, a previous study based on the Nigeria Demographic and Health Survey (NDHS2003) found that the prevalence of under-five death was highest among mother who belonged to Hausa/ Fulani/Kanuri ethnicity and lowest among those of Yoruba ethnicity [18]. Similar findings were reported by a study on NDHS-2008 as well, which found substantial differentials in under-five mortality risk by ethnic groups. For instance, risks of death were significantly lower for children of Yoruba, Igbo, and of the minority ethnic groups compared with those of Hausa/Fulani/ Kanuri tribes [12]. An earlier study comprising samples from 11 countries in sub-Saharan Africa also reported significant differences among ethnic groups in the odds of dying before reaching five years of age [22]. The same study also concluded that the potential child sur- vival inequalities among ethnic groups included urban residence, household economic situation, education attainment, mothers, use of maternal, and child health services [22].

\section{GENERAL DISCUSSION AND POLICY RECOMMENDATION}

The presence of a diverse ethnic groups who share varying cultural traits, values and norms, and health practices warrant the need for exploration of the existing ethnic disparities in fertility and child survival in Nigeria [18]. However, the current volume of research is inadequate to draw concrete evidence for the development of intervention programs. The subject is essentially qualitative in nature, hence the difficulty in understanding the precise mechanisms of having varying degrees of vulnerability to child mortality and fertility preference among different ethnic groups. A possible mechanism for this variation might be linked with socioeconomic characteristics such as living environment, educational attainment, types of profession, which are some of the crucial proximate determinants of maternal and child health [23-25]. Differences in health outcomes among ethnically diverse populations may reflect the interplay of genetic/biological factors with those surrounding environmental, lifestyle behaviour, and culture $[26,27]$. Sociocultural factors also play important roles in reproductive and child health, such as early marriages, number of marriages, and short intervals between births. Previous studies have shown that marital preferences vary substantially among ethnicities; for instance, the rate of polygyny among Hausa/Fulani/Kanuri tribes is twice as high as those of Yoruba [12]. Multiple marriages and higher fertility also contribute to higher child morbidity and mortality [28] because having many children in the same household could increase competition for household resources for food, education, and healthcare and result in compromised health status, especially if the household is poor [29].

At the macro level, political dominance of certain ethnic groups over others on public policy and resource allocation may favour some groups at the cost of disadvantaging the rest, which can fuel inequality and contribute to adverse health outcomes such as increased child mortality in the long run. Failure to maintain transparency and address ethnopolitical disputes can engender a cycle of disadvantage for certain ethnic groups, leading to reduced capacity among women to control their fertility through affordable family planning methods that are culturally appropriate. National policy making bodies should therefore take special steps to maintain transparency and make sure that programs are in place to eliminate ethnic disparities in healthcare delivery, especially in the areas of maternal and child health. Qualitative studies should be carried out to explore the ethnicity-specific reproductive behaviours that may lead to higher fertility and risk of child mortality. Also, the 
spatial distribution of ethnic groups is not homogenous within the regions; therefore, the regional differences in ethnic values/predictors that influence fertility behaviour and child survival remain open to further qualitative investigation.

\section{STRENGTHS AND LIMITATIONS}

This study has several strengths and limitations. This is the first study to show ethnic differences in parity and updated information of child deaths among the major ethnic groups in Nigeria. Also, the sample size was large and nationally representative. The limitations included the secondary nature of the data, which means that we had no control over the selection and measurement of variables. Because the analysis was quantitative, it was not possible to understand the cultural nuances that might have affected the associations. Child mortality was considered regardless of the exact cause of death; availability of this information would better indicate the risk factors attributable to ethnic affiliation. Despite the limitations in our findings, the present study is an important contribution to the current evidence on ethnic differences in fertility and child mortality studies and provides stimulation for further empirical research in this area.

\section{CONCLUSIONS}

The findings of the present study reaffirm those from previous ones regarding the strong differential influence of ethnic affiliation on child mortality in Nigeria. We also found a significant association between ethnicity and parity. However, these findings need to be substantiated by longitudinal investigations, especially into the mechanisms through which ethnicity exerts its role on fertility behaviour, and on healthcare practices that influence child survival. The findings also support the theory that women who experience child death are more likely to want to have more children. National fertility control programs should bear in mind the varying needs of the diverse and multi-ethnic population, and make strategic plans to make the healthcare system more sensitive to culture-specific needs, thus ensuring women's right to healthcare regardless of their social or ethnic background. Further research should be carried out to probe into the sources of inequities in the use of reproductive health services by women from different ethnic groups in Nigeria, who should be targeted with government strategies.

\section{COMPLIANCE WITH ETHICAL STANDARDS}

Informed consent was obtained from all individual participants included in the study. Procedures of MICS surveys are reviewed and approved by ICF Institutional Review Board (IRB), which ensures that the survey complies with the U.S. Department of Health and Human Services regulations for the protection of human subjects
(45 CFR 46), while the host country IRB ensures that the survey complies with the laws and norms of the nation [29]. New further institutional approval was necessary because the study was a secondary analysis of public domain data.

\section{DATA SOURCE}

Data used in this study are available through the MICS website: http://mics.unicef.org/surveysa

\section{ACKNOWLEDGEMENTS}

The authors wish to thank UNICEF MICS for the generous provision of the datasets that made this study possible. Data are available to the public upon registration through the official website of the MICS program.

\section{DISCLOSURE}

The authors report no conflict of interest.

\section{References}

1. Braveman P, Egerter S, Williams DR. The social determinants of health: coming of age. Annu Rev Public Health 2011; 32: 381-398.

2. Braveman P, Gottlieb L. The social determinants of health: it's time to consider the causes of the causes. Public Health Rep 2014; 129 (Suppl 2): 19-31.

3. Quadagno D, Sly DF, Harrison DF, et al. Ethnic differences in sexual decisions and sexual behavior. Arch Sex Behav 1998; 27 (1): 57-75

4. Odimegwu C, Somefun OD. Ethnicity, gender and risky sexual behaviour among Nigeria youth: an alternative explanation. Reprod Health 2017; 14 (1): 16.

5. Pflieger JC, Cook EC, Niccolai LM, Connell CM. Racial/ethnic differences in patterns of sexual risk behavior and rates of sexually transmitted infections among female young adults. Am J Public Health 2013; 103 (5): 903-909.

6. Kendall T, Bärnighausen T, Fawzi WW, Langer A. Towards comprehensive women's healthcare in sub-Saharan Africa: addressing intersections between HIV, reproductive and maternal health. J Acquir Immune Defic Syndr 2014; 67 (Suppl 4): S169-S172.

7. Wojcicki JM. Silence sexual and reproductive health discussions and we fuel the rise of HIV/AIDS in sub-Saharan Africa. Reprod Health 2017; 14 (1): 131.

8. Yaya S, Bishwajit G, Ekholuenetale M, Shah V. Inadequate utilization of prenatal care services, socioeconomic status, and educational attainment are associated with low birth weight in Zimbabwe. Front Public Health 2017; 5: 35.

9. Yaya S, Bishwajit G, Ekholuenetale M, et al. Timing and adequate attendance of antenatal care visits among women in Ethiopia. PLoS One 2017; 12 (9): e0184934.

10. Adedini SA, Odimegwu C, Imasiku EN, Ononokpono DN. Unmet need for family planning: implication for under-five mortality in Nigeria. J Health Popul Nutr 2015; 33 (1): 187-206.

11. Yaya S, Ekholuenetale M, Tudeme G, et al. Prevalence and determinants of childhood mortality in Nigeria. BMC Public Health 2017; 17 (1): 485. 
12. Adedini SA, Odimegwu C, Imasiku ENS, Ononokpono DN. Ethnic differentials in under-five mortality in Nigeria. Ethn Health 2015; 20 (2): 145-162.

13. Ukiwo U. The study of ethnicity in Nigeria. Oxf Dev Stud 2005; 33 (1): 7-23.

14. Obasohan PE. Religion, Ethnicity and Contraceptive Use among Reproductive age Women in Nigeria. Int J MCH AIDS 2015; 3 (1): 63-73.

15. Ekwochi U, Osuorah CDI, Ndu IK, et al. Food taboos and myths in South Eastern Nigeria: The belief and practice of mothers in the region. J Ethnobiol Ethnomed 2016; 12: 7

16. Babalola S, Fatusi A. Determinants of use of maternal health services in Nigeria--looking beyond individual and household factors. BMC Pregnancy Childbirth 2009; 9: 43.

17. Adedini SA, Odimegwu C, Bamiwuye O, et al. Barriers to accessing health care in Nigeria: implications for child survival. Glob Health Action 2014; 7: 23499.

18. Antai D. Inequalities in under-5 mortality in Nigeria: do ethnicity and socioeconomic position matter? J Epidemiol 2011 21 (1): 13-20

19. Antai D, Adaji S. Community-level influences on women's experience of intimate partner violence and terminated pregnancy in Nigeria: a multilevel analysis. BMC Pregnancy Childbirth 2012; 12: 128 .

20. Okolie VO, Cisana S, Schanfield MS, et al. Population data of 21 autosomal STR loci in the Hausa, Igbo and Yoruba people of Nigeria. Int J Legal Med 2018; 132 (3): 735-737.

21. National Bureau of Statistics (NBS) and United Nations Children's Fund (UNICEF). Multiple Indicator Cluster Survey 2016-17, Survey Findings Report. National Bureau of Statistics and United, Nations Children's Fund, Abuja 2017.

22. Brockerhoff $M$, Hewett P. Inequality of child mortality among ethnic groups in sub-Saharan Africa. Bull World Health Organ 2000; 78 (1): 30-41.

23. Joshi N, Bolorhon B, Narula I, et al. Social and environmental determinants of child health in Mongolia across years of rapid economic growth: 2000-2010. Int J Equity Health 2017; 16 (1): 189.

24. Kamiya Y. Socioeconomic determinants of nutritional status of children in Lao PDR: effects of household and community factors. J Health Popul Nutr 2011; 29 (4): 339-348.

25. Victorino CC, Gauthier AH. The social determinants of child health: variations across health outcomes - a population-based cross-sectional analysis. BMC Pediatr 2009; 9: 53.

26. Huddleston HG, Cedars MI, Sohn SH, et al. Racial and ethnic disparities in reproductive endocrinology and infertility. Am J Obstet Gynecol 2010; 202 (5): 413-419.

27. Ramírez M, Ford ME, Stewart AL, Teresi JA. Measurement issues in health disparities research. Health Serv Res 2005; 40 (5 Pt 2): 1640-1657.

28. Kanmiki EW, Bawah AA, Agorinya I, et al. Socio-economic and demographic determinants of under-five mortality in rural northern Ghana. BMC Int Health Hum Rights 2014; 14: 24.

29. Houle B, Stein A, Kahn K, et al. Household context and child mortality in rural South Africa: the effects of birth spacing, shared mortality, household composition and socio-economic status. Int J Epidemiol 2013; 42 (5): 1444-1454

\section{AUTHORS' CONTRIBUTIONS}

BG prepared the research concept and collected data. BG and SY wrote the article and finally approved the publication. SY critically reviewed the publication. 